\title{
A Kind of Rice Nitrogen Status Rapid Diagnostic Tool
}

\author{
Jin-heng Zhang, Xin Yu, Yongliang Lv, Zhenxuan Yao, \\ Dapeng Li, and Chao Han \\ Institute of Eco-environment \& Agriculture Information, \\ School of Environment and Safety Engineering, \\ Qingdao University of Science and Technology, \\ Qingdao, Shandong 266042, China
}

\begin{abstract}
Using data from three deformation positions $(680 \mathrm{~nm}, 730 \mathrm{~nm}$, and $765 \mathrm{~nm}$ ) of spectral reflectance and derivative spectra curves from red to near infrared spectral bands, red edge reflectance spectra index was developed. Nitrogen contents of rice canopy leaves were found to be significantly correlated with the red edge reflectance spectra index values at 0.01 probability level for different rice growth stages and genotypes studied. Four models established - for four rice growth stages were used to predict the nitrogen content of canopy leaves. Significant correlations were found between measured nitrogen contents and predicted nitrogen contents with high coefficient of determination $(\mathrm{R} 2=$ 0.97 ) at 0.01 probability level. Based on the four field experiments, we developed a new rice nitrogen status rapid diagnostic meter. The working principle of the meter was introduced, and the measuring accuracy of the meter was analyzed. Results showed that the precision of nitrogen status rapid diagnostic meter for predicting nitrogen content was more than $80 \%$ at tiller stage and more than $90 \%$ at booting stage at 0.01 probability level. The nitrogen status rapid diagnostic meter appears to be a promising tool for rapid, on-farm analysis of rice nitrogen status.
\end{abstract}

Keywords: Rice Nitrogen Content, Vegetation Index, Reflectance, Meter.

\section{Introduction}

Synthetic fertilizers especially nitrogen fertilizer have acquired a bad reputation in recent decades for causing serious ecological damage when farmers use them excessively. Nitrogen status of various crops is an very important factor which can reflect the nitrogen apply level. In agricultural research, organic chemical constituents have been successfully measured by using multiple linear regression to relate the constituents of interest to the reflectance spectra of dried ground samples. Approximately 42 minor absorption features in the visible and near-infrared portions of the spectrum have been successfully correlated with foliar chemical contents, including those of nitrogen, protein, and lignin as demonstated [1]. Nitrogen status of various crops has been related to reflectance at certain wavelength, and various reflectance ratios and indices have been used to detect nitrogen deficiencies in plants as demonstrated [2-4]. Many 
relationships between the spectral response of crops and growth factors have been elucidated, based on reflectance obtained from handheld and aircraft-mounted sensors providing images in visible and other parts of the electromagnetic spectrum. More recently these procedures have been extended to the laboratory analysis of dried ground foliage as demonstrated [5] and fresh forest foliage as demonstrated [6]. Spectral determination has been proved to be an automatic, quick, and nondestructive method for assessment of nutrients.

Spectroscopy can provide information about a substance by relating its interaction with electromagnetic radiation as a function of wavelength to its chemical composition and physical properties. Spectral bands in the visible and near-infrared regions of the spectrum have been used to develop a number of indices for estimating nitrogen content. Vegetation index is a simple, effective, and experiential measurement of terrestrial vegetation activity, and plays a very important role in qualitative and quantitative remote sensing. Most of the indices based on reflectance spectrum including single band spectral reflectance and reflectance band ratios or difference have been used as indicators of nitrogen content.

Some studies have been conducted to measure nitrogen content of crops using field spectrometry. The nitrogen status of various crops has been related to reflectance at specific wavelength, and various reflectance ratios and indices have been used as indicators of nitrogen deficiencies in plants as demonstrated [2-4] [7-13]. Spectral determinations can provide an automatic, quick, and nondestructive method for estimating crop nutrient status.

As a fundamental research tool for the application of current and future hyperspectral and even multi-spectral sensing systems, a field spectroradiometer was used to collect reflectance data. But, until now, there is no report on predicting the nitrogen content of rice using handheld spectral meter. Therefore, the purpose of this study was to verify the feasibility and effectiveness of a newly developed RERI Nitrogen Meter to diagnose rice nitrogen nutrient content.

\section{Materials and Methods}

\subsection{Experimental Description}

Four field experiments were conducted in 2002, 2009, and 2010.The first experiment was conducted in a ploughed field of $3.02 \mathrm{hm} 2$ near JiaShan County of Zhejiang Province (Latitude $30.84^{\circ}$, Longitude $120.92^{\circ}$ ). The field was divided into three $\mathrm{N}$ supply areas: an area of $0.47 \mathrm{hm} 2$ did not receive any $\mathrm{N}$ fertilizer, an area of $0.23 \mathrm{hm} 2$ received half of the recommended rate, and the remainder of the field received the recommended rate. The recommended $\mathrm{N}$ application rates were $135 \mathrm{~kg}$ urea $\mathrm{hm}-2$, $202.5 \mathrm{~kg}$ urea $\mathrm{hm}-2$, and $120 \mathrm{~kg}$ urea hm-2 for tiller, booting, and heading stage, respectively. Three genotypes of rice (Oryza sativa L) were used: late rice 101, late rice C-67, and late rice 004 .

The second field experiment was laid out in a split-plot design with three replications at Yuhang Town, Hangzhou City, Zhejiang Province (Latitude $30.43^{\circ}$, Longitude $120.3^{\circ}$ ). The main plots were arranged in a randomized complete block and consisted of six basal $\mathrm{N}$ rates: $0,150,225,300,375$, and $450 \mathrm{~kg} \mathrm{~N} \mathrm{hm-2}$. Subplots were seeded 
with two genotypes of late rice, Bing 9363 and Bing 9652, which had the same growth cycles and different foliar colors (dark and bright, respectively). The main plot size was $5.0 \mathrm{~m} \times 3.6 \mathrm{~m}$ with four repeats.

The third field experiment was extended over $0.7 \mathrm{hm} 2$ at Chengyang Qingdao of Shandong Province (Latitude $36.07^{\circ}$, Longitude $120.33^{\circ}$ ). It was designed in a randomized complete block with three replications, using three varieties of rice, Shengdao 13, Lindao 11, and Yangguang 200, with similar growth stages. Four basal nitrogen (N) rates were used: $0 \mathrm{~kg}$ urea hm-2, $270 \mathrm{~kg}$ urea hm-2, $585 \mathrm{~kg}$ urea hm-2, and $750 \mathrm{~kg}$ urea hm-2.

The fourth field experiment was laid out in a split-plot design with three replications at Yutai town, Jining city (Latitude $35^{\circ}$, Longitude $116.65^{\circ}$ ), Shandong province. The main plots were arranged in a randomized complete block and consisted of 4 basal $\mathrm{N}$ rates: $0,156,310$, and $403 \mathrm{~kg} \mathrm{~N} \mathrm{hm-2.} \mathrm{Subplots} \mathrm{were} \mathrm{seeded} \mathrm{with} \mathrm{three} \mathrm{genotypes} \mathrm{of}$ rice (Zhendao88, Shengdao16, and Shengdao15), which had similar growth cycles. The main plot size was $5.0 \mathrm{~m} \times 8 \mathrm{~m}$ with three repeats.

For the 1st, 2nd and 3rd field experiments, 50\%, 40\%, and 10\% $\mathrm{N}$ fertilizer was applied before transplanting, at tillering, and at heading, respectively. But for the 4th field experiments, $\mathrm{N}$ fertilizer was applied according to the following ratio: $20 \%$ before transplanting, $55 \%$ at tillering, and $20 \%$ at heading.

\subsection{Canopy Reflectance Spectrum Measurements and Plant Sampling}

In the first and second field experiments, rice canopy reflectance at 350-2500 $\mathrm{nm}$ in 1-nm-wide wavebands were measured using the portable spectroradiometer FieldSpec FR held $70 \mathrm{~cm}$ above the canopy top. In the third and fourth field experiments, the reflectance spectrum was measured at $350-1100 \mathrm{~nm}$ in 2.4-nm-wide waveband by the portable spectroradiometer AvaSpec-2048FT-SPU held $100 \mathrm{~cm}$ above the canopy top using the controllable field spectral measurement device (China patent of invention 200810180572.7) (see figure 1). All canopy reflectance spectra were measured under cloudless conditions and as close to solar noon as possible.

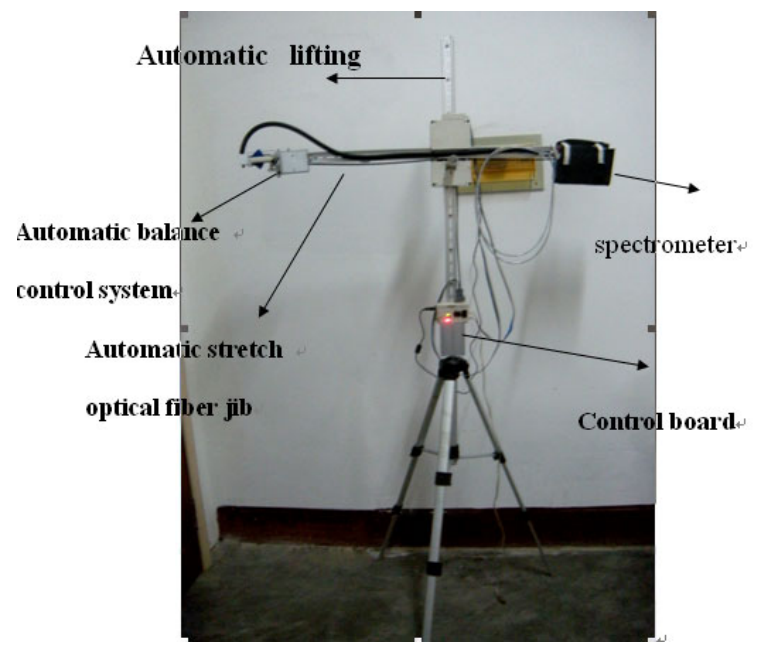

Fig. 1. Controllable field spectral measurement device (China patent of invention 200810180572.7) 
After measuring the reflectance spectra, several rice clumps were obtained and their leaves were used as subsamples. Total $\mathrm{N}$ was determined for the subsamples based on the Kjeldahl method. Total $\mathrm{N}$ was expressed in $\mathrm{g} \mathrm{N}$ kg-1 dry weight.

\section{Results and Analysis}

\subsection{The Feasibility and Effectiveness of Vegetation Index and Prediction Models}

The RERI standard bands were selected according to Figure 2. The following equation was developed to estimate the canopy leaf $\mathrm{N}$ content [14]

$$
R E R I=\frac{R_{765}-R_{730}}{R_{730}-R_{680}}
$$

Where, Ri indicates the rice canopy reflectance at the band $\mathrm{i}(\mathrm{nm})$.

According to the reference [14], the RERI increased with increasing $\mathrm{N}$ levels (the 1st, 2nd and 3rd experiments). Correlation coefficients between RERI and the $\mathrm{N}$ content were significant at 0.01 probability level for eight rice genotypes in the 1 st, 2 nd and 3rd experiments.

The relationship between RERI and the canopy $\mathrm{N}$ content can best be described by linear regression models of the form $y=a x+b$. Data from the third experiment were used in canopy leaf $\mathrm{N}$ content prediction models (Table 1) [14].

The models described in Table 1 were tested using two validation data sets from the first and second experiments. The canopy reflectance spectra of the validation samples were used to calculate RERI, and the algorithm equations were used to predict canopy leaf $\mathrm{N}$ content. We observed good agreement between the predicted and measured values (Table 2). A high positive correlation was observed between the predicted and actual $\mathrm{N}$ contents [14].

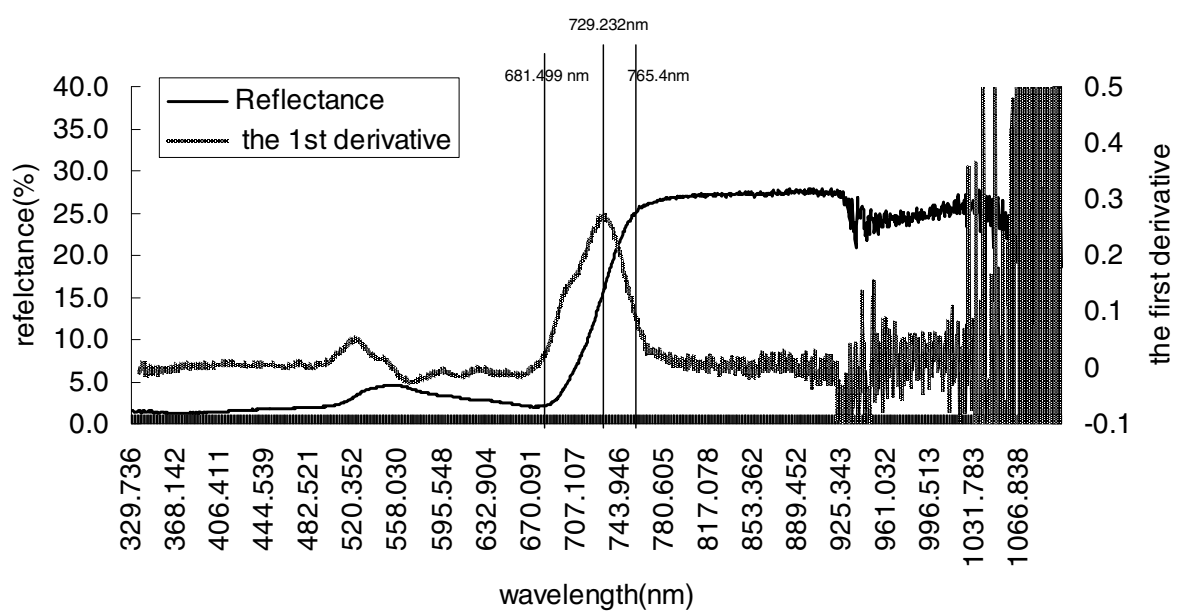

Fig. 2. Special wavebands of the first derivative and reflectance spectrum curves of rice canopy 
Analysis of the visible/NIR canopy reflectance and canopy leaf $\mathrm{N}$ content for a wide range of rice experiments allows the development of better algorithms for quantifying the $\mathrm{N}$ content from canopy reflectance spectra. With better algorithms, new (satellite) sensors of remote sensing can be developed. The RERI developed in the present study could be used to accurately estimate the $\mathrm{N}$ fertilizer level and canopy leaves' $\mathrm{N}$ contents. Regression analysis indicated that RERI was a better indicator of the canopy leaves' $N$ contents. The power of predictors and prediction models was tested using two validation datasets, and revealed good agreement between the predicted and measured canopy leaves' $\mathrm{N}$ contents. We concluded that satisfactory results were obtained using the new vegetation index RERI to predict the rice $\mathrm{N}$ nutrient status.

\subsection{Introduction of RERI Nitrogen Meter}

According to the research described above, the meter (figure3, figure4) only records three wavelengths of rice canopy spectral reflectance. Recording speed for testing and spectral reflectance can reach millisecond timescale. The meter accomplishes data rectification, processing, and recording functions automatically and intelligently. The meter performs simply and fast, without requiring manual intervention which can avoid the influence of human factors. The micro processing system will record canopy spectral reflectance at wavelengths of $680 \mathrm{~nm}, 730 \mathrm{~nm}$, and $765 \mathrm{~nm}$. RERI values are calculated using the following formulas:

$$
\mathfrak{R}_{680}=k_{1} \frac{\lambda_{680}}{\eta_{680}} \quad \mathfrak{R}_{730}=k_{2} \frac{\lambda_{730}}{\eta_{730}} \quad \text { and } \quad \Re_{765}=k_{3} \frac{\lambda_{765}}{\eta_{765}}
$$

( $k_{1}, \mathrm{k}_{2}, \mathrm{k}_{3}$ are the corresponding error correction coefficients).
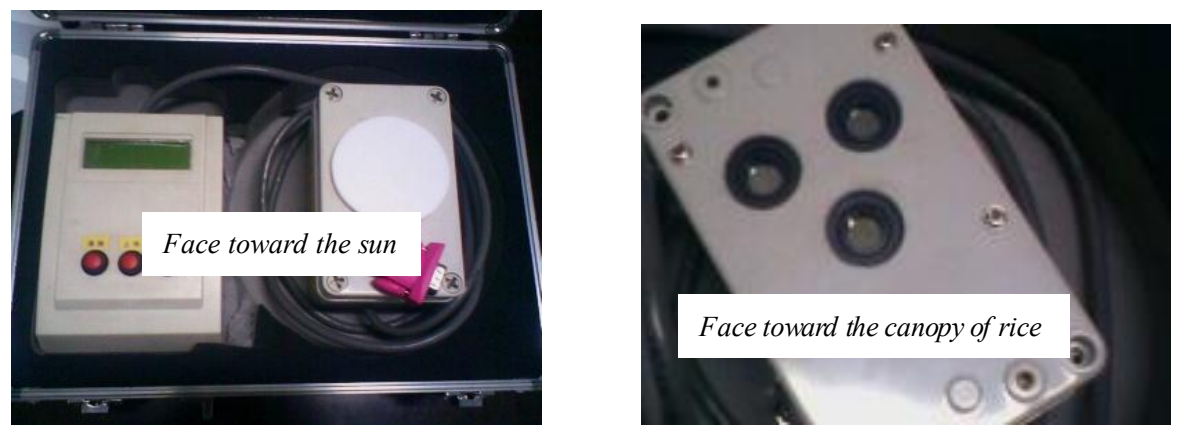

Fig. 3. RERI sensor meter 

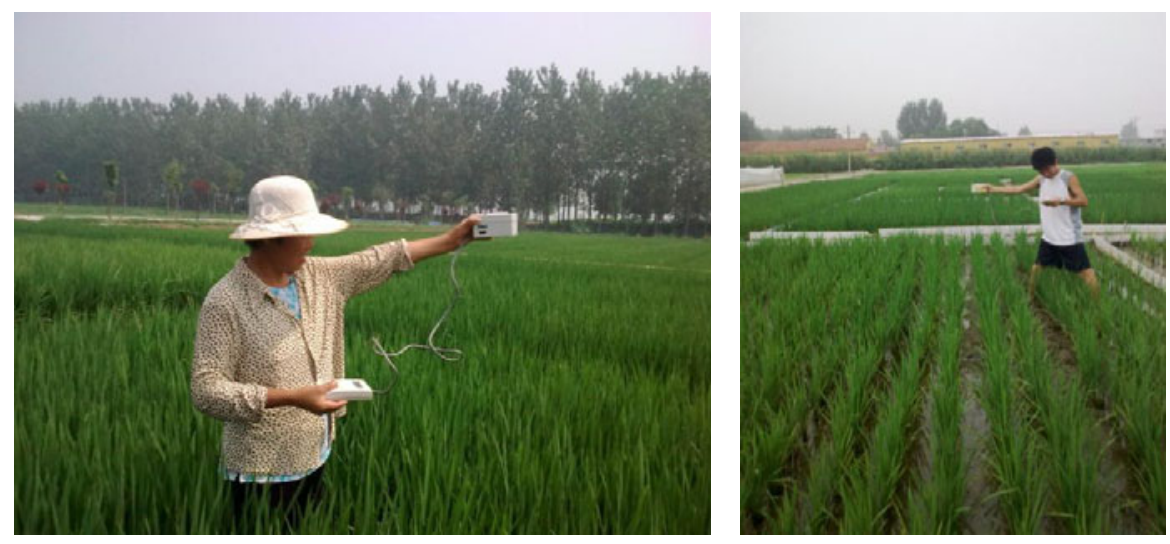

Fig. 4. RERI sensor used in field experiment. (In the 4th field experiment, handheld RERI sensor was used to measure rice canopy RERI values. The handheld RERI sensor was held $100 \mathrm{~cm}$ above the canopy under cloudless or partly cloudy conditions.)

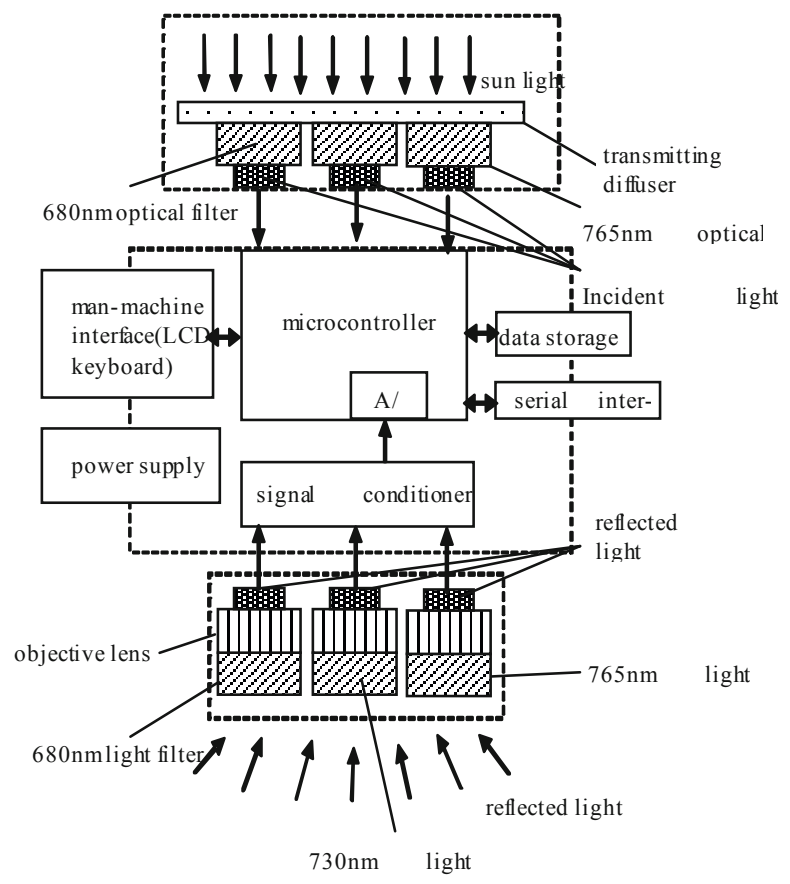

Fig. 5. Working principle diagram

This meter uses sunshine as light source and optical filters as optical components to measure the reflectance of crops at $680 \mathrm{~nm}, 730 \mathrm{~nm}$, and $765 \mathrm{~nm}$. Then, the RERI values are calculated. Low power consumption TI single-chip with six filtering systems 
is used as core component. Three filtering systems are installed under the transmitting diffuser which is on the top of the instrument (toward sun). Sun light reaches the sensors after going through transmitting diffuser and optical filter. Then, the sun optical signals at $680 \mathrm{~nm}, 730 \mathrm{~nm}$, and $765 \mathrm{~nm}$ are obtained. The next set of three filtering systems is installed on the bottom of the instrument (toward crop canopy). The filtering systems installed on the bottom of the instrument collect canopy reflected light and send them to the sensors after going through optical filter and objective lens. Subsequently, the crop canopy reflected light signals are obtained. Every channel signal is transformed into digital signals through Analog-to-Digital Converter. RERI values are calculated with digital signals. Meanwhile the results are shown on the LCD. All data files are stored in the memory and they can be downloaded on to a computer by RS 232 or USB serial port (figure 5). Nitrogen content of rice canopy is automatically calculated and displayed by the onboard software (figure 6).

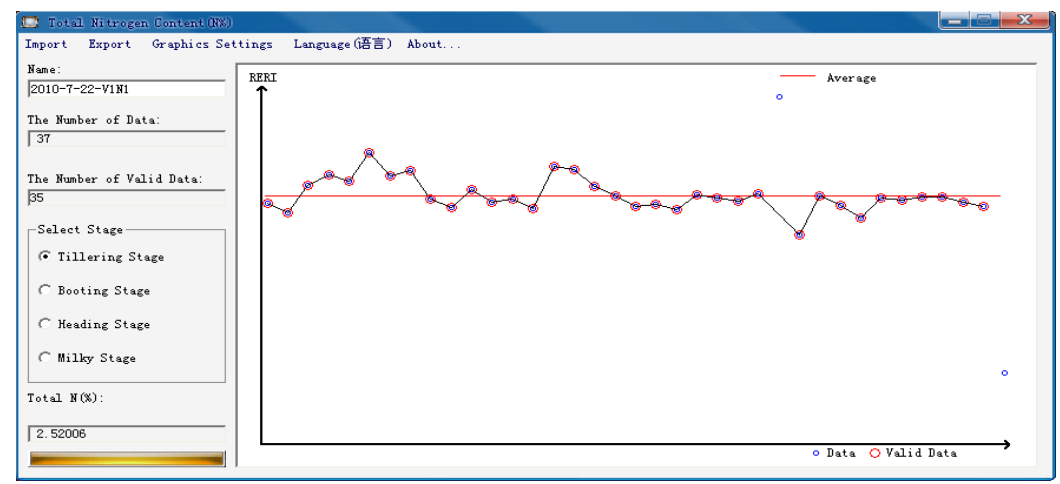

Fig. 6. Software for elimination of coarse errors and calculation of nitrogen content. (Rice genotype is Zhendao88. Tiller stage. The line is the average line. Small circles are the measured data using RERI sensor. Big circles are the valid data after removing coarse errors.)

\subsection{Elimination of Coarse Errors and Calculation of Nitrogen Content}

In order to ensure the accuracy of RERI Nitrogen Meter, when using RERI Nitrogen Meter, we should select as many repetition points as possible (at least 30). Because of the milliseconds response time, very short time will be spent on measuring process.

A software with data processing function was developed to select and eliminate errors caused by operation processes while predicting the nitrogen content (N\%) (see figure 6). When the number of data points is less than or equal to 30, Romanvschi rule ( $\mathrm{T}$ distribution) is used, otherwise Grubbs rule is used to remove coarse errors from the measured data. In this software, measured data files can be imported by selecting the menu "import". Then, the file name and the amount of data are shown automatically. After selecting rice growth stages, object models will be called by the software to calculate the nitrogen content automatically. The results are saved as log files. 


\subsection{Verification of the Precision of Diagnosis}

The precision of diagnosis of RERI Nitrogen Meter was verified by using the data from the 4th experiment. In addition, the meter's feasibility and practicability were also confirmed.

Comparing the RERI values calculated from canopy spectral reflectance with those measured by the RERI Nitrogen Meter showed that calculated values were significantly correlated to the measured values (correlation coefficients more than 0.8). Significant correlation coefficients were more than 0.7 between the RERI Nitrogen Meter readings and the level of nitrogen fertilizer. Both measured RERI using RERI Nitrogen Meter and calculated RERI using spectral reflectance increased with increasing nitrogen fertilizer levels (figure 7). As expected, when the growth stages changed from tiller to heading stage, RERI Nitrogen Meter readings increased (figure 8).

After importing RERI Nitrogen Meter readings from the 4th experiment into the onboard software (figure 6), the regression models (table 1) were called and the nitrogen contents of rice canopy leaves were shown automatically. Correlation analysis between the $\mathrm{N}$ content predicted by the RERI Nitrogen Meter and the $\mathrm{N}$ content measured using the common laboratory Dumas method showed that the precision of total $\mathrm{N}$ content diagnosis was more than $80 \%$ at tiller stage and $90 \%$ at booting stage at the 0.01 probability level (table 3 ).

Therefore, this study indicated that the RERI Nitrogen Meter can not only qualitatively classify the level of nitrogen, but can also be used for quantitative diagnosis of rice nitrogen content of canopy leaves. The precision of diagnosis reaches $80-90 \%$ and even higher.

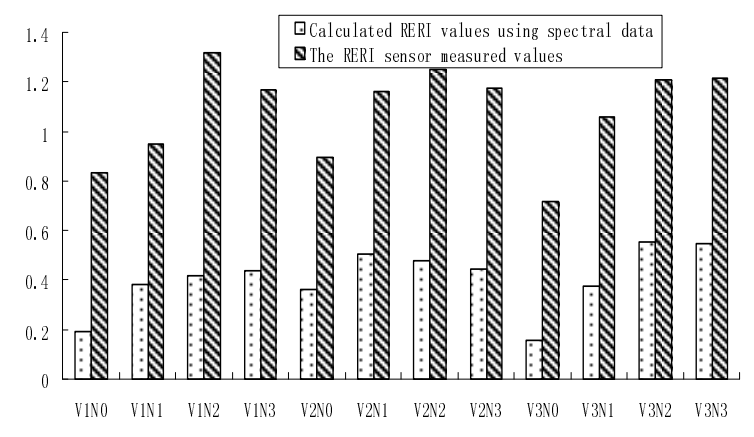

(2010.7.22)

Fig. 7. RERI values among genotypes and fertilizer levels. (V1:Zhendao88, V2:Shengdao16, V3:Shengdao15) 


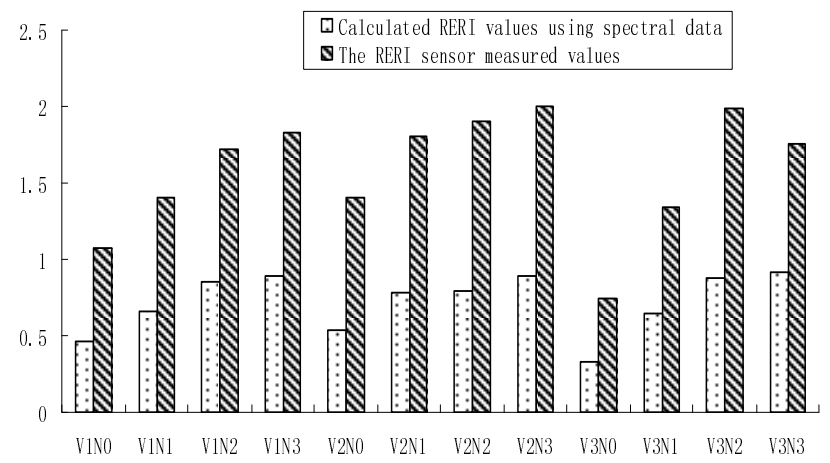

(2010.8.3)

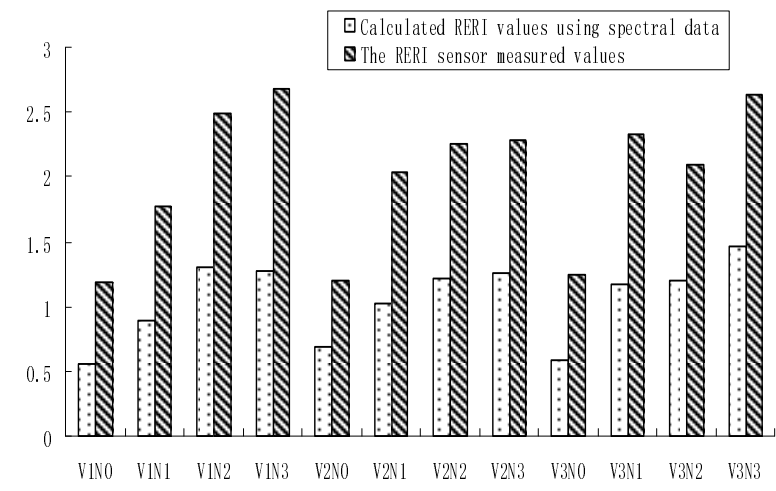

(2010.8.16)

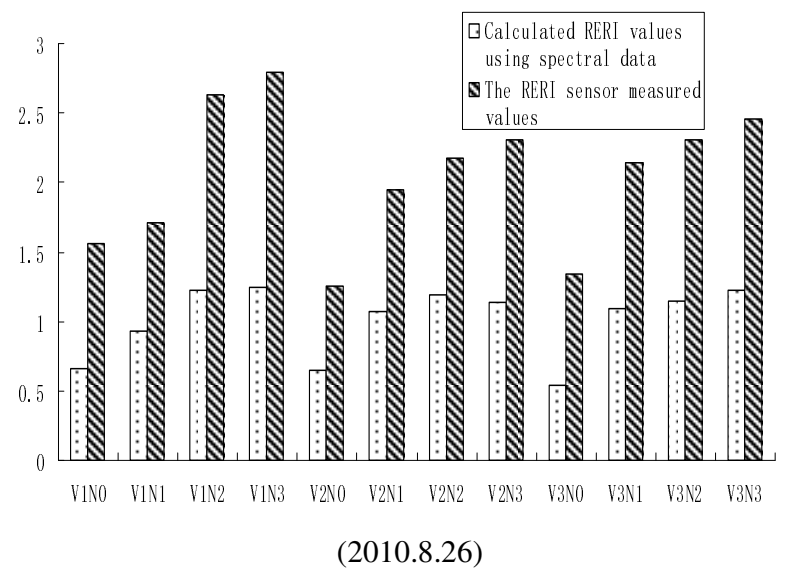

Fig. 7. (continued) 


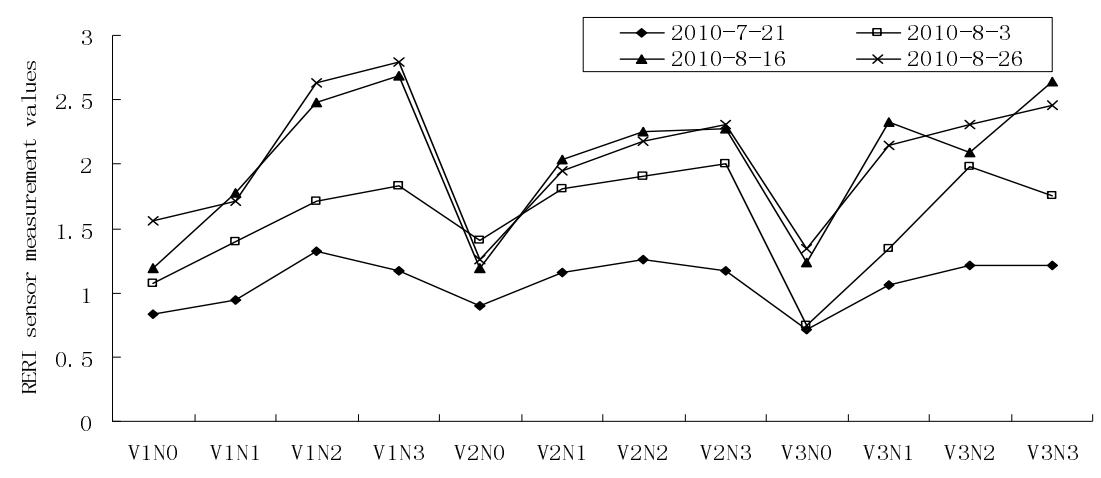

Fig. 8. RERI sensor measurement values among growth stages (V1:Zhendao88, V2:Shengdao16, V3:Shengdao15)

Table 1. Canopy leaf nitrogen content prediction models $(n=12)[14]$ (The third field experiment)

\begin{tabular}{llllll}
\hline Stage & Model & $\mathrm{R}$ & $\mathrm{R}^{2}$ & $\mathrm{~F}$ & $\mathrm{P}$ \\
\hline Tiller & $\mathrm{N} \%=1.2007 \mathrm{RERI}+1.384$ & 0.919 & $0.844^{* *}$ & 43.389 & 0.000 \\
Booting & $\mathrm{N} \%=0.7408 \mathrm{RERI}+1.5727$ & 0.888 & $0.788^{* *}$ & 29.777 & 0.000 \\
Heading & $\mathrm{N} \%=0.8618 \mathrm{RERI}+1.5364$ & 0.801 & $0.642^{* *}$ & 17.911 & 0.002 \\
Milky & $\mathrm{N} \%=0.7809 \mathrm{RERI}+1.5889$ & 0.663 & $0.439^{*}$ & 7.824 & 0.019 \\
\hline
\end{tabular}

Table 2. Correlation between predicted and actual nitrogen contents in the first and second field experiments [14]

\begin{tabular}{cccccc}
\hline \multicolumn{2}{c}{ Experiment/Stage } & $\mathrm{R}$ & $\mathrm{R}^{2}$ & $\mathrm{~F}$ & Sig. \\
\hline \multirow{2}{*}{ First Experiment $(\mathrm{n}=$} & Tiller & $0.931^{* *}$ & 0.866 & 200.240 & 0.000 \\
32) & Booting & $0.966^{* *}$ & 0.933 & 430.024 & 0.000 \\
& Heading & $0.973^{* *}$ & 0.946 & 564.014 & 0.000 \\
Second Experiment & Tiller & $0.861^{* *}$ & 0.742 & 28.689 & 0.000 \\
$(\mathrm{n}=12)$ & Jointing & $0.946^{* *}$ & 0.896 & 85.756 & 0.000 \\
& Booting & $0.964^{* *}$ & 0.930 & 131.897 & 0.000 \\
& Heading & $0.984^{* *}$ & 0.969 & 308.563 & 0.000 \\
\hline
\end{tabular}


Table 3. Verification of RERI sensor's measuring precision (Fourth field experiment. V1:Zhendao88, V2:Shengdao16, V3:Shengdao15) $(* *$ indicates significant correlation at 0.01 level)

\begin{tabular}{|c|c|c|c|c|c|c|}
\hline & & Predicted N\% & Measi & $\mathrm{F}$ & Sig. & $\mathrm{R}^{2}$ \\
\hline \multirow{12}{*}{$\begin{array}{c}2010-8-3 \\
\text { Tiller stage }\end{array}$} & V1N0 & 2.67 & 2.60 & \multirow{25}{*}{38.875} & \multirow{25}{*}{$0.000 * *$} & \multirow{25}{*}{0.7954} \\
\hline & V1N1 & 3.06 & 3.23 & & & \\
\hline & $\mathrm{V} 1 \mathrm{~N} 2$ & 3.44 & 3.71 & & & \\
\hline & V1N3 & 3.58 & 3.73 & & & \\
\hline & $\mathrm{V} 2 \mathrm{~N} 0$ & 3.07 & 2.99 & & & \\
\hline & $\mathrm{V} 2 \mathrm{~N} 1$ & 3.55 & 3.20 & & & \\
\hline & $\mathrm{V} 2 \mathrm{~N} 2$ & 3.67 & 3.78 & & & \\
\hline & V2N3 & 3.79 & 4.00 & & & \\
\hline & V3N0 & 2.28 & 2.63 & & & \\
\hline & V3N1 & 2.99 & 3.02 & & & \\
\hline & V3N2 & 3.77 & 3.56 & & & \\
\hline & V3N3 & 3.49 & 3.85 & & & \\
\hline \multirow{14}{*}{$\begin{array}{c}2010-8-16 \\
\text { Booting stage }\end{array}$} & & & & & & \\
\hline & V1N0 & 2.45 & 2.33 & & & \\
\hline & V1N1 & 2.89 & 2.73 & & & \\
\hline & $\mathrm{V} 1 \mathrm{~N} 2$ & 3.41 & 3.10 & & & \\
\hline & V1N3 & 3.56 & 3.08 & & & \\
\hline & $\mathrm{V} 2 \mathrm{~N} 0$ & 2.46 & 2.36 & & & \\
\hline & $\mathrm{V} 2 \mathrm{~N} 1$ & 3.08 & 2.64 & & & \\
\hline & $\mathrm{V} 2 \mathrm{~N} 2$ & 3.24 & 2.87 & & & \\
\hline & $\mathrm{V} 2 \mathrm{~N} 3$ & 3.26 & 3.03 & & & \\
\hline & V3N0 & 2.49 & 2.46 & & & \\
\hline & V3N1 & 3.30 & 3.11 & & & \\
\hline & V3N2 & 3.12 & 2.77 & & & \\
\hline & V3N3 & 3.53 & 3.11 & & & \\
\hline & & & & 108.107 & $0.000 * *$ & 0.9153 \\
\hline
\end{tabular}

\section{Conclusions}

A RERI Nitrogen Meter developed based on red edge reflectance index (RERI) was investigated for practical application in agricultural production management. Based on the investigation, it can be concluded that because of the millisecond response time and the precision of diagnosis more than $80 \%$, the meter can be used as a rapid nitrogen content diagnostic tool, and is suitable for not only handheld but also low altitude platforms such as helicopters and hot air balloons. Practical applications indicated that 
RERI Nitrogen Meter is suitable for real time diagnosis of nitrogen content from canopy level, and should be an important part of the precision agriculture technology to improve variable fertilization technology.

Acknowledgments. Project supported by the Hi-Tech. Research and Development Program of China (863 Program) (2007AA10Z205) and the National Natural Science Foundation of China (40601062).

\section{References}

1. Curran, P.J.: Remote sensing of foliar chemistry. Remote Sensing of Environment 30, 271-278 (1989)

2. Goel, P.K., Prasher, S.O., Landry, J.A., Patel, R.M., Bonnellr, R.B., Viau, A.A., Miller, J.R.: Potential of airborne hyperspectral remote sensing to detect nitrogen deficiency and weed infestation in corn. Computers and Electronics in Agriculture 38, 99-124 (2003)

3. Serrano, L., Filella, I., Peñuelas, J.: Remote sensing of biomass and yield of winter wheat under different nitrogen supplies. Corp SCI 40(3), 723-730 (2000)

4. Lukina, E.V., Raun, W.R., Stone, M.L., Solie, J.B., Johnson, G.V., Lees, H.L., Ruffa, J.M., Phillips, S.B.: Effect of row spacing, growth stage, and nitrogen rate on spectral irradiance in winter wheat. Journal of Plant Nutrition 23(1), 103-122 (2000)

5. Card, D.H., Peterson, D.L., Matson, P.A., Aber, J.D.: Prediction of leaf chemistry by the use of visible and near in-frared reflectance spectroscopy. Remote Sensing of Environment 26, 123-147 (1988)

6. Curran, P.J., Dungan, J.L., Macler, B.A., Plummer, S.E., Peterson, D.L.: Reflectance spectroscopy of fresh whole leaves for the estimation of chemical content. Remote Sensing of Environment 39(2), 153-166 (1992)

7. Zhang, J.H.: Rice nitrogen nutrition diagnosis using continuum-removed reflectance. Journal of Plant Ecology 30(1), 78-82 (2006)

8. Zhang, J.H., Wang, K., Bailey, J.S., Wang, R.C.: Predicting nitrogen status of rice using multispectral data at can-opy scale. Pedsphere 16(1), 108-117 (2006)

9. Strachan, I.B., Pattey, E., Boisvert, J.B.: Impact of nitrogen and environmental conditions on corn as detected by hyperspectral reflectance. Remote Sensing of Environment 80, 213-224 (2002)

10. Blackmer, T.M., White, S.E.: Using precision farming technologies to improve management of soil and fertilizer nitrogen. Aust J. Agric. Res. 49(3), 555-564 (1998)

11. Ma, B.L., Morrison, M.J., Dwyer, L.M.: Canopy light reflectance and field greenness to assess nitrogen fertilization and yield of maize. Agron J. 88(6), 915-920 (1996)

12. Buschmann, C., Nagel, E.: In vivo spectroscopy and internal optics of leaves as basis for remote sensing of vegetation. Int. J. Remote Sens. 14(4), 711-722 (1993)

13. Gamon, J.A., Peñuelas, J., Field, C.B.: A narrowwaveband spectral index that tracks diurnal changes in photosynthetic efficiency. Remote Sensing of Environment 41, 35-44 (1992)

14. Zhang, J., Lv, Y., Han, C., Li, D., Yao, Z., Jiang, X.: New Reflectance Spectral Vegetation Indices for Estimating Rice Nitrogen Nutrition III: Development of a New Vegetation Index Based on Canopy Red-Edge Reflectance Spectra to Monitor Rice Canopy Leaf Nitrogen Concentration. Sensor Lett. 9, 1201-1206 (2011) 